\title{
VOICE BREAKING IN MALES RESULTS IN SEXUAL DIMORPHISM OF GREEN WOODHOOPOE CALLS
}

\author{
by
}

\begin{abstract}
ANDREW N. RADFORD ${ }^{1,2)}$
(Department of Zoology, University of Cambridge, Downing Street, Cambridge, CB2 3EJ, UK, and Percy FitzPatrick Institute of African Ornithology, University of Cape Town, Rondebosch 7701, South Africa)
\end{abstract}

(Acc. 2-III-2004)

\begin{abstract}
Summary
Ontogenetic changes and sexual differences in the acoustic structure of green woodhoopoe (Phoeniculus purpureus) 'kek' calls were investigated in a wild population. At fledging, the calls of males and females were indistinguishable in terms of fundamental frequency, frequency modulation, peak frequency and call duration. After 3-5 months, however, the male voice 'broke' (i.e. underwent a significant decrease in fundamental frequency), while there was no change in female call structure. Consequently, the fundamental frequency of adult male calls was $48 \%$ lower than that of adult females, and there was no overlap in the call frequencies of the sexes in adulthood. The change in male voice occurred within a 23 week period and no intermediate call frequencies were recorded. The timing of the voice break did not correspond with a change in overall body size, suggesting that growth of the syrinx was not the proximate cause. However, it did coincide with the stage in development when male bill length grew to exceed that of all females and when males began to lose their distinctive brown throat patch, providing some indirect evidence that hormonal control may be important.
\end{abstract}

1) e-mail address: ar255@cam.ac.uk

2) I thank Frank, Shaun and Vernon Cockin, Bill Dutton, Willem Fourie and Mike Putzier for unlimited access to their land. I also thank Morné du Plessis for access to his long-term data set and for useful discussions throughout the project. I am grateful to Ian Burfield, Nick Davies, Camilla Hinde, Tim Fawcett, Joah Madden and Jim Reynolds for helpful comments on earlier versions of the manuscript, and Oliver Krüger for statistical advice. The work was supported by a Natural Environment Research Council studentship and a Junior Research Fellowship from Girton College, Cambridge.

(C) Koninklijke Brill NV, Leiden, 2004

Behaviour 141, 555-569

Also available online - 


\section{Introduction}

Sexual differences in avian calls are widespread (Ballintijn \& ten Cate, 1997a) and manifest themselves in two main ways: (1) vocalisations produced by one sex but not the other, such as the territorial and mate-attraction calls common to many songbirds (Catchpole, 1982; Kroodsma \& Miller, 1996); and (2) vocalisations produced by both sexes, but with different acoustic structures, such as different frequency characteristics, temporal patterning or syntax (e.g. Rosenfield \& Bielefeldt, 1991; Farquhar, 1993; Ballintijn \& ten Cate, 1997a). Much early work suggested that simple, stereotypic calls remain acoustically the same from hatching to adulthood (e.g. Marler et al., 1961; Lade \& Thorpe, 1964; Nottebohm \& Nottebohm, 1971). However, an increasing number of studies have demonstrated that while some calls do indeed seem to be fixed on hatching, others change with age (ten Thoren \& Bergmann, 1987; Groothuis, 1989; Groothuis et al., 1993). Changes in frequency and amplitude are most likely to be related to ontogenetic changes in the anatomy of the syrinx (Würdinger, 1970; Platz, 1974; Abs, 1980), while more complex changes in frequency modulations and duration may also involve changes in the central nervous system (Groothuis, 1989).

Song development in oscines has long been an important subject for studies on the ontogeny of behaviour (e.g. Kroodsma, 1982; Catchpole \& Slater, 1995). In contrast, several important aspects of vocal development in nonpasserines have, with the exception of studies on imitators like parrots, received little attention so far (but see e.g. Groothuis, 1989; Ballintijn \& ten Cate, 1997b). Among these are questions concerning whether, when and how sex differences arise. Answers to these questions not only give an insight into the ontogeny of calling but, since vocalisations are signals for communication, they also provide clues as to which acoustic features carry which types of information.

The green (or red-billed) woodhoopoe (Phoeniculus purpureus) is a highly vocal species found in cooperatively breeding groups of 2-12 individuals in South Africa (du Plessis, 1991). Woodhoopoes of both sexes produce a variety of calls, including a cackle that forms the basis of inter-group territorial displays (Ligon \& Ligon, 1978; Radford, 2003), a movementinitiation call (Radford, 2004), an anti-predator alarm call (Fry et al., 1988), and a 'kek' call that may function to maintain contact between dispersed 
group members and/or serve to mediate spacing between foraging competitors (Radford, in press). Ligon \& Ligon (1990) suggested that all these vocalisations are sexually diagnostic among adults, but no data have been previously presented to show this. Hence, the first aim of this paper is a quantitative acoustic analysis of woodhoopoe kek calls.

By measuring frequency and temporal characteristics of the kek call, I investigated which vocal parameters are sexually dimorphic in the green woodhoopoe. I focussed on this particular vocalisation because it was the easiest to record from individuals (two group members rarely overlapped in their kek calling, and keks were given at a rate of less than one per second). Furthermore, as keks are heard whenever group members are within $15 \mathrm{~m}$ of one another, I expected to be able to collect a sufficient number of calls for each individual and age-class.

The second aim of this paper is an investigation of when the sexual differences in acoustic structure of the kek call arise. I demonstrate that the vocalisations of male and female green woodhoopoes are similar on fledging. I show that the male voice 'breaks' (i.e. undergoes a rapid decrease in fundamental frequency) after 3-5 months, resulting in the divergence of male and female calls. I then discuss possible proximate causes of the male voice break, including growth of the syrinx and elongation of the bill, and consider the potential role of hormonal changes.

\section{Methods}

Study species

Twenty-five colour-ringed groups of green woodhoopoes were studied near Morgan's Bay $\left(32^{\circ} 43^{\prime} \mathrm{S}, 28^{\circ} 19^{\prime} \mathrm{E}\right)$, Eastern Cape Province, South Africa, from November to May in 1999/ 2000 and 2000/2001, and from November to February in 2001/2002. Each group consisted of between two and eight individuals (mean \pm SE: $3.5 \pm 0.3$ ) that defended an all-purpose territory throughout the year. Green woodhoopoes in this area inhabit riverine forest, which forms belts along river valleys (du Plessis, 1989). Valleys are separated by open grassland, which is not used by the birds.

Since green woodhoopoes become physiologically capable of reproducing after one year (M.A. du Plessis pers. comm.), birds older than 12 months were classified as adults. Adults could be sexed on the basis of bill length (Radford \& du Plessis, 2003). Four months after fledging, there are no further changes in linear measures of body size, and male bill length exceeds that of females (Radford \& du Plessis, 2003), so individuals aged 4-12 months were referred to as 'full-grown' juveniles. Birds fledging less than four months previously were classified as 'growing' juveniles. Since an accurate measure of juvenile age was important, juvenile vocalisations were only recorded from individuals of known fledging date. Growing 
juveniles could be sexed on the presence (males) or absence (females) of a brown throat patch, which is lost before adulthood (Ligon \& Ligon, 1978). Due to the timing of field seasons, too few data were collected on the vocalisations of individuals aged 4-12 months to enable statistical analysis. This paper therefore focuses on four categories of individual: adult males, adult females, growing juvenile males and growing juvenile females.

\section{Recording and analysing vocalisations}

Kek calls are given in both foraging and non-foraging (e.g. preening and resting) situations, but calls from the same individual do not differ acoustically in the two cases (Radford, in press). Thus, keks were recorded whenever they were heard, from 41 adult males, 38 adult females and 32 juveniles, of which 17 were subsequently recorded the following year after reaching adulthood. Individuals were recorded on $15 \pm 3$ separate days (range: 8-22 days), with at least 10 keks recorded each time. All calls were recorded on 60 min TDK tapes using a Sennheiser MKH416T directional gun microphone (with wind shield) and a WM-D6C Sony Professional Walkman. Recordings were made from within 5-15 $\mathrm{m}$ of the foraging individual. Although the variation in recording distance may influence the amplitude of the call on the tape, there was no systematic bias in recording distances between individuals.

Using a random-number procedure, a set of 20 suitable keks was selected from those recorded for each individual. Calls distorted by background noise or by overlap with calling from other members of the group were discarded. No two keks given by the same individual in the same foraging bout were used (a foraging bout was defined as the time a group spent in one particular area without moving more than $30 \mathrm{~m}$ in a single flight). Using Canary version 1.2 (Cornell Laboratory of Ornithology, 1993), each call was digitised (sample rate of $44,100 \mathrm{~Hz}, 16-$ bit precision) and stored in a computer file. To obtain the frequency profile of a call, sound spectrograms were generated (based on a fast Fourier transformation of 1024 points, time resolution of $3 \mathrm{~ms}$, 50\% overlap and Hamming window), with a frequency resolution of $43 \mathrm{~Hz}$.

Four vocal parameters of the kek call were measured, and a mean value calculated for each parameter from the 20 selected calls of each individual. (1) The fundamental frequency was established from the spectrogram of a particular call (see Fig. 1) using the on-screen cursors that moved in increments of $8 \mathrm{~Hz}$. The cursor was placed on the part of the fundamental which corresponded to the frequency with the greatest amplitude. (2) I used the difference between the minimum and maximum frequency of the fundamental as an indicator of the extent of frequency modulation. To enable more accurate on-screen resolution while calculating these measures, energies which fell $300 \mathrm{~Hz}$ above or below the fundamental were filtered out. This removed background noise from a range which contained no fundamental-frequency energy. (3) Peak frequency was taken as the frequency at peak amplitude and was automatically calculated by the software from amplitude spectra. (4) The duration of the call was established from the waveform. Individual keks contained up to 14 harmonics (maximum frequency: adult males $=$ ca. $7 \mathrm{kHz}$, adult females $=$ ca. $14 \mathrm{kHz}$ ), but they were not all visible on every spectrogram. It was therefore impossible to determine accurately the maximum frequency or the number of harmonics produced in each case.

\section{Morphometric measurements}

Morphometric measures were available from birds caught between 1981 and 2001, as part of a long-term study (M.A. du Plessis, pers. comm.). Birds were caught in nets placed over 
roost holes before dawn. Bill length (the chord between the tip of the bill and the anterior edge of the cere) was measured to the nearest $0.1 \mathrm{~mm}$ with dial callipers. Wing length (the distance from the carpal joint to the tip of the longest primary) was determined to the nearest millimetre with a stopped rule. Wing length was used as a linear measure of overall body size, since it is the best such predictor, at least in passerines (Gosler et al., 1998).

\section{Statistical analysis}

Since there were no significant correlations between any of the four measured variables (all $r<0.19$, all $p>0.05$ ), kek-call parameters were analysed separately. Vocal parameters were normally distributed and so an ANOVA was used to compare each one between the four categories of individual. Sequential Bonferroni corrections were applied in the case of multiple comparisons with the same data set (Rice, 1989). Paired $t$-tests were used to compare individuals that were recorded both as juveniles and as adults. To determine whether kek calls could be assigned to individuals of different sex and age class according to their acoustic structure, I performed a stepwise discriminant function analysis (DFA) using the four measured vocal parameters. When analysing morphometric changes, $\log _{\mathrm{e}}$-transformed data were used. They were first checked for normality and $t$-tests or Mann-Whitney $U$-tests used accordingly. Statistical tests were two-tailed and significance was established at $p<0.05$. Summary statistics are presented as mean \pm SE.

\section{Results}

\section{Development of sexual dimorphism}

The keks of growing juvenile males and females did not differ significantly in any of the four measured acoustic parameters (Table 1). A comparison of the vocal parameters of individuals recorded as both growing juveniles and adults revealed a significant decrease in male fundamental frequency ('voice break') with age, but no significant change in female frequency (Table 2). Male frequency modulation also decreased with age, although not significantly after Bonferroni correction. There was no age-related change in female frequency modulation, nor in peak frequency or call duration in either sex.

The male voice break resulted in sexual dimorphism of adult woodhoopoe frequencies: keks of adult males had fundamental frequencies than were $48 \%$ lower than those of adult females (Table 1). The kek calls of adult males and adult females did not differ significantly in their frequency modulation, peak frequency or call duration. DFA indicated a successful discrimination of adult males from the other three age-sex categories based on the fundamental frequency (Wilk's $\lambda=0.15, F_{3,107}=207.21, p<0.001$ ). There 
TABLE 1. Frequency and temporal characteristics of green woodhoopoe kek calls

\begin{tabular}{lccccc}
\hline Vocal parameter & $\begin{array}{c}\text { Adult male } \\
(41)\end{array}$ & $\begin{array}{c}\text { Juvenile male } \\
(14)\end{array}$ & $\begin{array}{c}\text { Adult female } \\
(38)\end{array}$ & $\begin{array}{c}\text { Juvenile female } \\
(18)\end{array}$ & $F_{3,107}$ \\
\hline Fundamental & $492 \pm 10^{\mathrm{a}}$ & $809 \pm 21^{\mathrm{b}}$ & $873 \pm 14^{\mathrm{b}}$ & $890 \pm 19^{\mathrm{b}}$ & $207.25^{* * *}$ \\
$\quad$ frequency (Hz) & $(375-597)$ & $(696-967)$ & $(705-1042)$ & $(678-982)$ & \\
Frequency & $705 \pm 9$ & $726 \pm 16$ & $730 \pm 10$ & $744 \pm 13$ & $2.31^{+}$ \\
$\quad$ modulation (Hz) & $(610-820)$ & $(630-820)$ & $(620-830)$ & $(640-820)$ & \\
Peak frequency & $1531 \pm 26$ & $1534 \pm 51$ & $1476 \pm 29$ & $1494 \pm 41$ & $0.82^{+}$ \\
$\quad(\mathrm{Hz})$ & $(1226-1823)$ & $(1227-1803)$ & $(1101-1847)$ & $(1167-1834)$ & \\
Duration (ms) & $35.1 \pm 0.5$ & $34.2 \pm 0.8$ & $36.1 \pm 0.4$ & $35.1 \pm 0.6$ & $2.09^{+}$ \\
& $(29.5-40.2)$ & $(30.4-39.4)$ & $(32.1-40.0)$ & $(31.9-40.0)$ & \\
\hline
\end{tabular}

Twenty calls were sampled, and the call parameters averaged, from 111 separate individuals. Individuals older than one year were classified as adults, while juvenile refers to those still growing (i.e. individuals that had been fledged for less than four months). Shown are means $\pm \mathrm{SE}$ (with range in parentheses) for the relevant number of individuals. $F$-values are from a separate ANOVA for each vocal parameter, ${ }^{+}$not significant, ${ }^{* * *} p<0.001$, with sequential Bonferroni corrections. Different superscripts indicate which age-sex categories of individual differed significantly (Tukey's post-hoc test).

TABLE 2. Changes with age in frequency and temporal characteristics of green woodhoopoe kek calls

\begin{tabular}{lccccccc}
\hline Vocal parameter & \multicolumn{2}{c}{ Male $(N=8)$} & \multirow{2}{*}{$t$} & & \multicolumn{2}{c}{ Female $(N=9)$} & \multirow{2}{*}{$t$} \\
\cline { 2 - 3 } & As juvenile & As adult & & As juvenile & As adult & \\
\hline Fundamental & $797 \pm 32$ & $518 \pm 23$ & $6.20^{* * *}$ & $891 \pm 20$ & $840 \pm 23$ & $2.05^{+}$ \\
$\quad$ frequency (Hz) & $(696-967)$ & $(409-596)$ & & & $(773-962)$ & $(753-960)$ & \\
Frequency & $726 \pm 16$ & $684 \pm 18$ & $2.93^{+}$ & $763 \pm 17$ & $749 \pm 17$ & $1.73^{+}$ \\
$\quad$ modulation (Hz) & $(650-810)$ & $(610-760)$ & & $(690-840)$ & $(680-810)$ & \\
Peak frequency & $1497 \pm 66$ & $1547 \pm 77$ & $0.50^{+}$ & $1451 \pm 61$ & $1437 \pm 49$ & $0.17^{+}$ \\
$\quad(H z)$ & $(1227-1803)$ & $(1226-1823)$ & & $(1167-1710)$ & $(1227-1641)$ & \\
Duration (ms) & $32.9 \pm 1.0$ & $35.4 \pm 39.8$ & $2.14^{+}$ & $35.5 \pm 1.0$ & $34.8 \pm 1.2$ & $0.42^{+}$ \\
& $(30.4-39.4)$ & $(33.4-39.8)$ & & $(32.0-40.0)$ & $(30.4-40.0)$ &
\end{tabular}

Shown are mean $\pm \mathrm{SE}$ (with range in parentheses) for the same eight males and nine females. Juvenile refers to those still growing (i.e. individuals that had been fledged for less than four months), while adults were older than one year. Twenty calls were sampled, and the call parameters averaged, for each individual in each age class. $t$-values are from paired $t$-tests, ${ }^{+}$not significant, ${ }^{* * *} p<0.001$, with sequential Bonferroni corrections. 


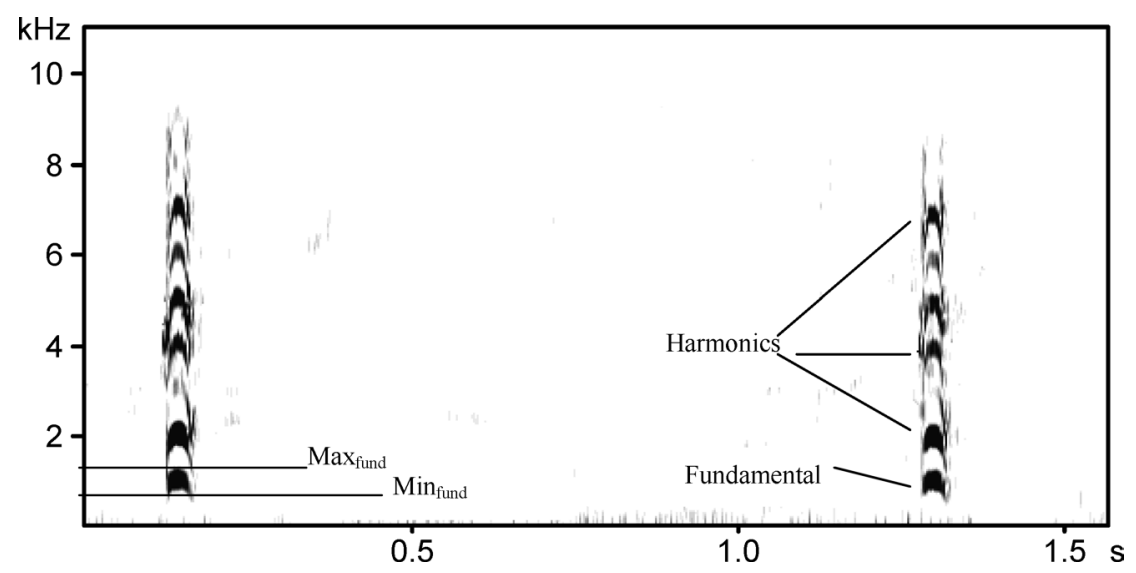

Fig. 1. Spectrogram depicting two 'kek' calls given by an adult female green woodhoopoe. Up to 14 harmonics were apparent in some calls, but variability in the sharpness of recordings prevented an accurate assessment of this feature. An indicator of frequency modulation of the fundamental was obtained by taking the difference between the maximum frequency $\left(\operatorname{Max} x_{f u n d}\right)$ and the minimum frequency $\left(\operatorname{Min}_{\text {fund }}\right)$ of the fundamental. Call duration was measured from the waveform for greater accuracy.

was no overlap between the fundamental frequency range of adult males and those of the other three categories (Table 1). Hence, the model correctly classified $100 \%$ of adult males. However, it was less successful in discriminating between the other three categories (successful discrimination: adult females $=15.8 \%$, growing juvenile males $=57.1 \%$, growing juvenile females $=50.0 \%$ ) as a result of the extensive overlap in vocal parameters, as exemplified by the scatterplot of the first two discriminant functions (Fig. 2).

Analysing the coefficient of variation of the kek-call parameters (i.e. an indicator of call stereotypy) revealed no significant differences between the sexes (ANOVA: all $F_{1,107}<1.20$, all $p>0.10$ after Bonferroni correction). Growing juveniles exhibited larger variation than adults in the fundamental frequency and the frequency modulation of their kek calls, but the results were not significant after sequential Bonferroni correction (ANOVA: all $F_{1,107}<5.40$, all $p>0.05$ ).

\section{The voice break}

The change in male vocalisation frequency occurred approximately 14-16 weeks after fledging (Fig. 3). At the same stage in development, there was no change in the frequency of female vocalisations. Figure 3 suggests that 


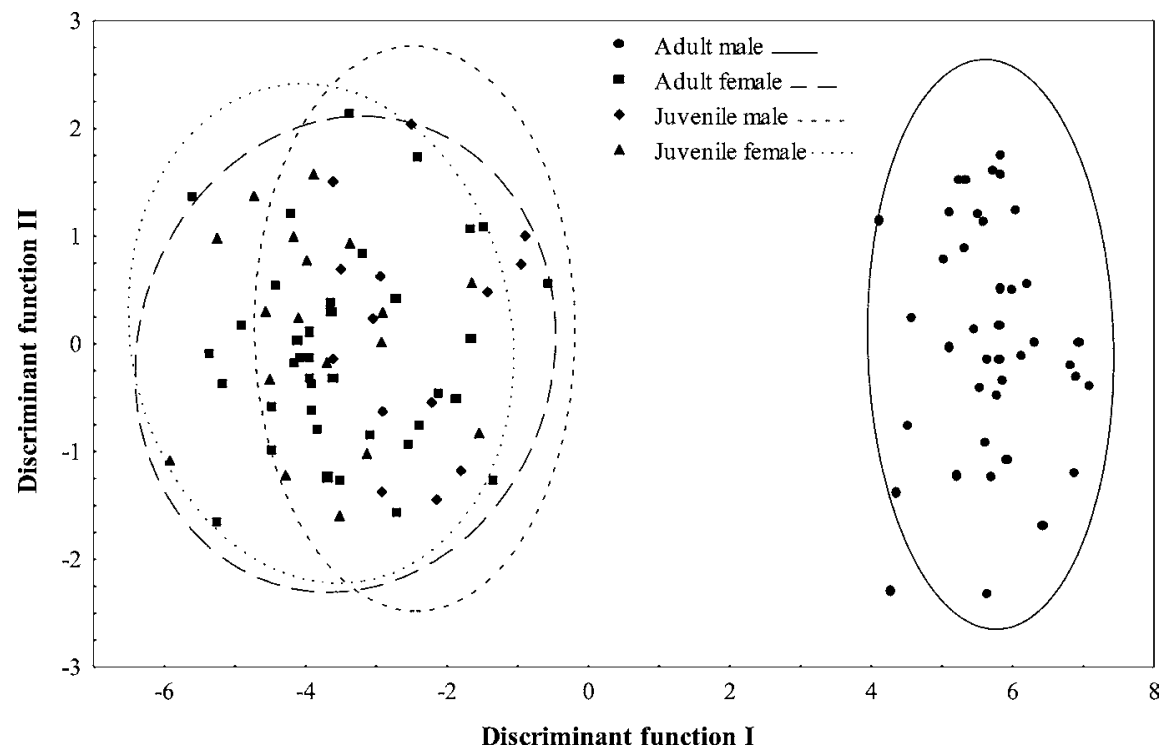

Fig. 2. Scatterplot of the two discriminant function scores (I and II) for the kek calls of 111 green woodhoopoes. Ellipses give the $95 \%$ confidence intervals of the category centroids.

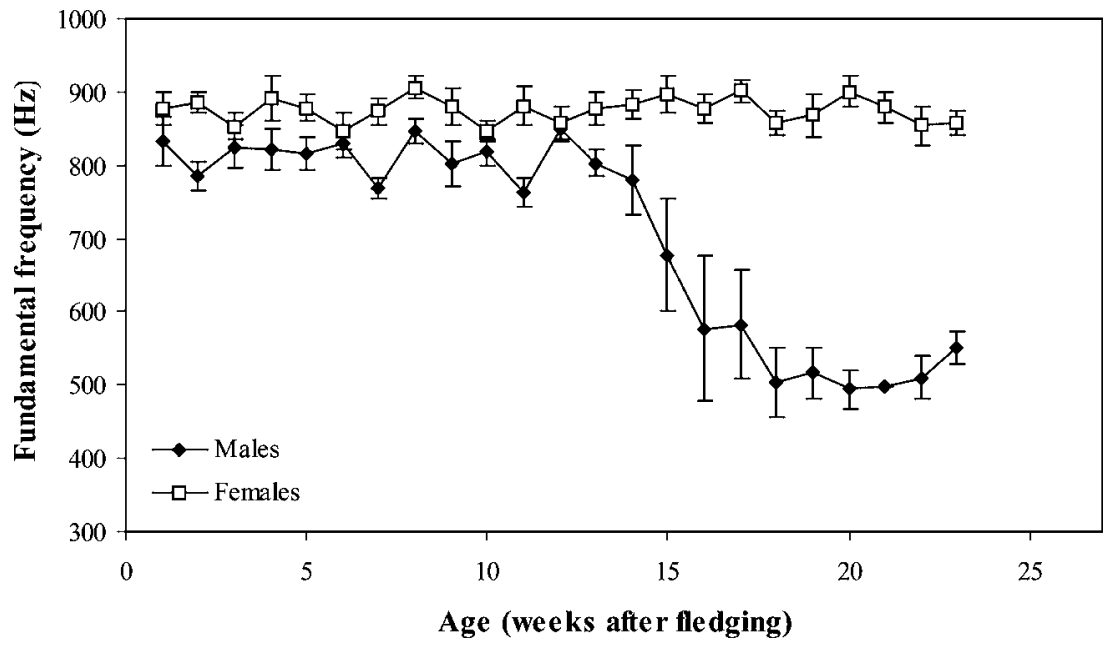

Fig. 3. Changes in the fundamental frequency of juvenile green woodhoopoe kek calls with increasing age. Recordings were made from 13 males and 14 females, although data were not available from all individuals at each age. Shown are means \pm SE. 


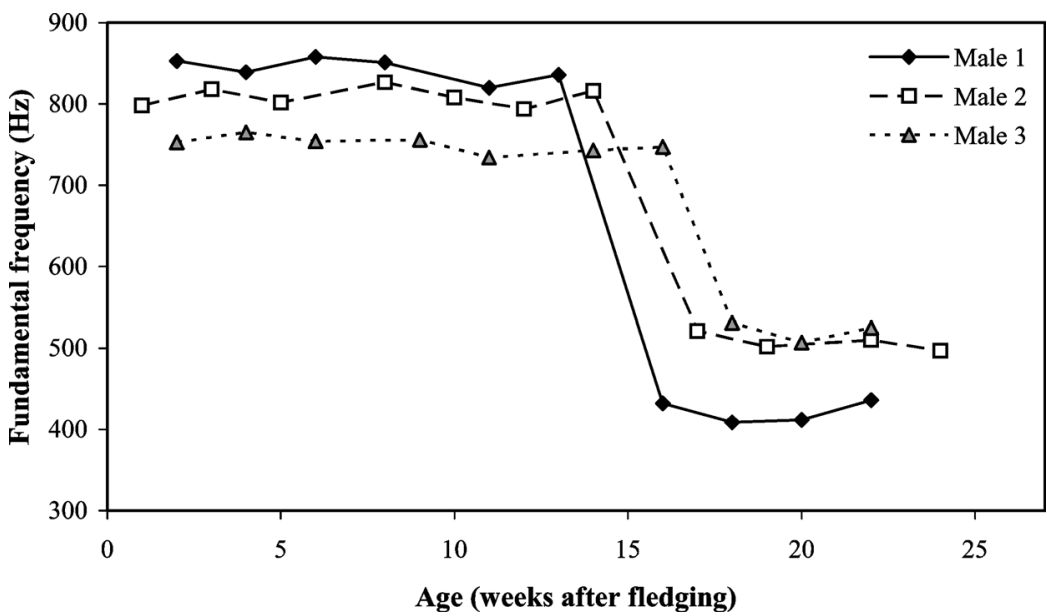

Fig. 4. Changes in the fundamental frequency of kek calls with increasing age in three juvenile male green woodhoopoes. Each point represents the mean of three calls.

there might be a transitional stage during which intermediate call frequencies are produced by males. However, no calls of intermediate frequency were heard or recorded during this study (all calls recorded from 13 males between 12 and 18 weeks after fledging had fundamental frequencies $>740 \mathrm{~Hz}$ or $<570 \mathrm{~Hz}$ ), and data from three individuals followed in detail for 22-25 weeks after fledging suggested that a male's voice broke relatively suddenly (Fig. 4). The appearance of a gradual change in Figure 3 is therefore likely to result from different individuals experiencing the sudden voice break at different times after fledging (range: 11-19 weeks, $N=13$ males).

At the same stage of development as the male voice break, there was no significant increase in wing length, for either males (1-3 months after fledging $=137.7 \pm 0.5 \mathrm{~mm}, 4-6$ months $=138.4 \pm 0.6 \mathrm{~mm} ; t_{47}=0.91$, $p=0.370)$ or females $(1-3$ months $=129.3 \pm 0.8 \mathrm{~mm}, 4-6$ months $=$ $130.6 \pm 0.5 \mathrm{~mm}$; 2-sample $t$-test: $t_{48}=1.54, p=0.130$; Fig. 5a). However, bill length did increase significantly at this stage in development in both males (1-3 months after fledging $=39.0 \pm 1.2 \mathrm{~mm}, 4-6$ months $=55.8 \pm$ $0.6 \mathrm{~mm}$; Mann-Whitney $U$-test: $U=302, N_{1}=24, N_{2}=25, p<0.001$ ) and females $(1-3$ months $=36.5 \pm 1.1 \mathrm{~mm}, 4-6$ months $=44.4 \pm 0.4 \mathrm{~mm}$; $\left.U=193, N_{1}=18, N_{2}=32, p<0.001\right)$. Although there was no sudden change in bill length, this was the stage during which male bill length grew to exceed that of all females (Fig. 5b). 

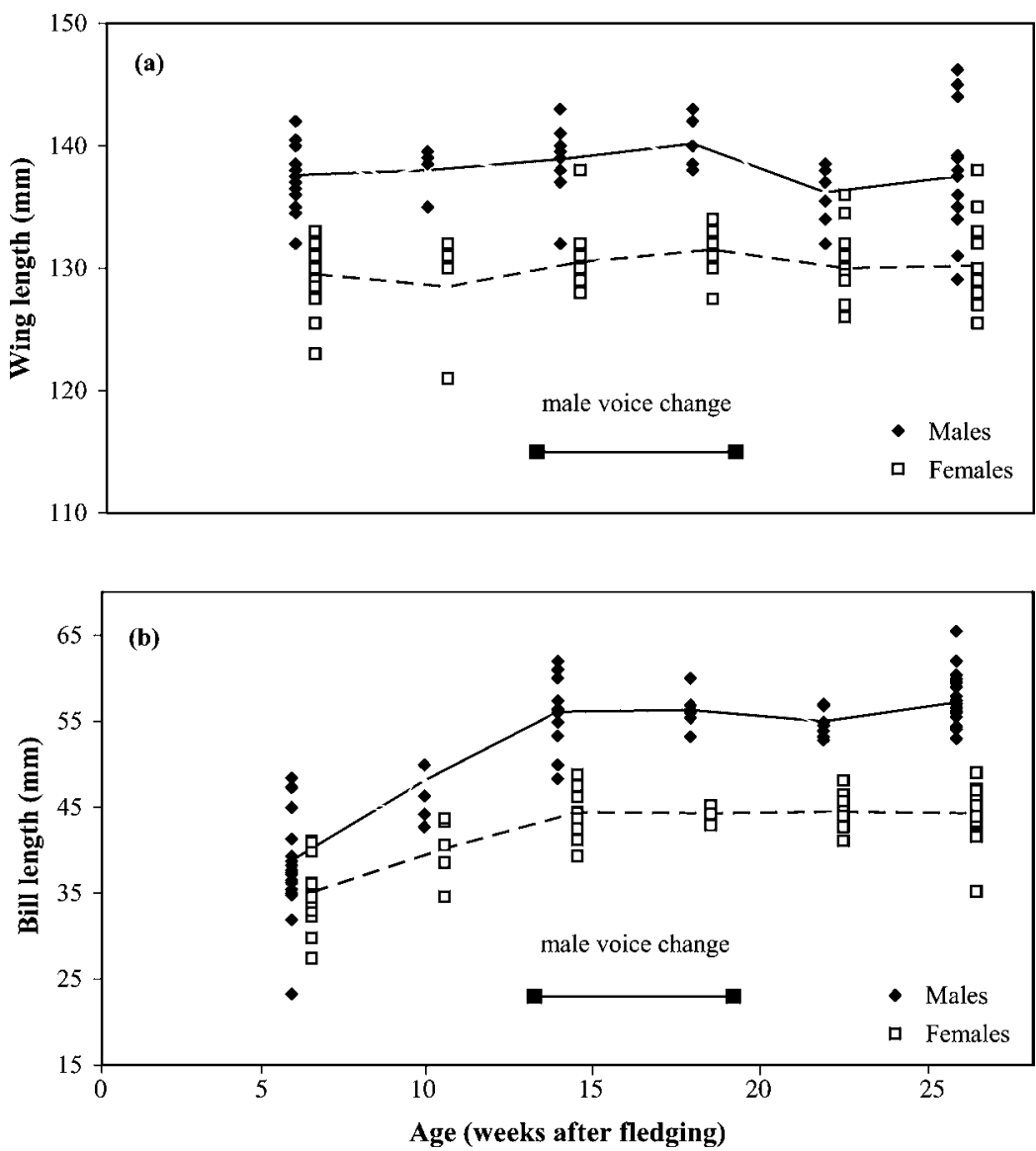

Fig. 5. Age-related changes in: (a) wing length (as an indicator of overall body size); and (b) bill length of juvenile green woodhoopoes. Lines are drawn through the means at each age. Each point represents a different individual ( males $=68$, females $=73$ ).

\section{Discussion}

The kek calls of green woodhoopoe fledglings of both sexes had a similar fundamental frequency to those of adult females. Sexual differences in frequency became apparent approximately 14-16 weeks after fledging, when the male voice 'broke' and became lower in frequency, matching adult male calls in nature. The sexual dimorphism in adult call frequency is obvious to the human ear (Ligon \& Ligon, 1990; pers. obs.), thus providing a reliable means of sexing individuals in the field, and is likely to be easily perceived by the birds themselves (Dooling, 1982). A divergence in call structure of 
the sexes as a result of male change has also been recorded in barnacle geese (Branta leucopsis): males exhibited a gradual and continuous pitch descent over approximately 70 days (ten Thoren \& Bergmann, 1987). In the Anseriformes and Galliformes, generally, voice breaking can take several weeks, during which time the body and syrinx show a large and rapid growth (Würdinger, 1970; Platz, 1974; Abs, 1980). In the green woodhoopoe, however, the breaking of the male voice seemed to occur relatively rapidly. Although individuals were not followed daily, so brief transitional periods may have been missed, no intermediate frequencies were recorded at any stage in the study. It is possible that males refrain from calling during the transition period, but individuals would need to be followed continuously to test this.

In most avian species, as in woodhoopoes, females produce higher frequency vocalisations than males (e.g. Bretagnolle, 1989; Robisson, 1992; Ballintijn \& ten Cate, 1997a). However, a number of non-passerines exhibit reversed sexual dimorphism in call frequency (e.g. Rosenfield \& Bielefeldt, 1991; Farquhar, 1993), usually explained by the female being the larger sex. Sex differences in body size are likely to be reflected in the size of the soundproducing organ (Myers, 1917; Ballintijn \& ten Cate, 1997a), with a larger syrinx resulting in a lower frequency of sound produced (between species: Ryan \& Brenowitz, 1985; within species: Würdinger, 1970), although the precise linkage between sound structure and syringeal morphology remains unclear. Given that adult male green woodhoopoes are 5-8\% larger than adult females in most linear measures (Radford \& du Plessis, 2003), the intersexual difference in body size might be expected to explain the lower frequency of adult male calls. However, there was no change in body size (as reflected by wing length) when the male voice broke. Although syringeal measures are needed to confirm that its growth and physical maturation are not directly responsible for the sexual differences in woodhoopoe vocalisations, it is known that the syrinxes of some species (e.g. doves and pigeons) are already fully developed before the voice breaks (Abs, 1980).

There are a number of other potential proximate causes of the change in male call frequency. For example, after initial production in the syrinx, the tonal quality of a sound may be modified in the suprasyringeal vocal tract (Nowicki, 1987; Podos, 1997; Beckers et al., 2003a). At the same time that male kek calls became lower in frequency, there was a significant increase in bill length. However, bill morphology could not influence the fundamental frequency, which is determined at the sound source (Fletcher \& Tarnopolsky, 
1999). Alternatively, a changed pattern of beak usage by males may change the volume and thus the resonance properties of their vocal tracts. That is, there may be a lower fundamental frequency present in the calls of females as well, but this is suppressed by a vocal tract volume that favours the transmission of higher frequencies. However, there were no diminished energy peaks visible on the amplitude spectra of females and the peaks occurred at intervals which did not suggest the presence of a hidden fundamental (A.N. Radford, unpubl. data). Finally, the sudden drop in fundamental frequency may be the result of a phenomenon known as 'mode-locking' (Beckers et al., 2003b), which results from the nonlinear dynamics of the syrinx (Fee et al., 1998). The syrinx structure in males may gradually diverge from that in females, and then the voice suddenly breaks because of intrinsic dynamics.

Recent findings have demonstrated that the calls of non-oscines are hormonally influenced during their development (Groothuis \& Meeuwissen, 1992; Groothuis et al., 1993; Fusani et al., 1994). Hormonal changes might affect neural control centres, as well as causing subtle physiological alterations in vocal-tract structure (Harries et al., 1998), in turn causing changes in the spectral nature of calls. Hence, in the green woodhoopoe, increased androgen levels could lead, indirectly, to the lowering of call frequencies seen in males. Although blood samples were not available to test this hormonal theory, indirect evidence comes from a concurrent modification in male plumage. Many plumage changes are well known to be the consequence of hormonal fluctuations (Owens \& Short, 1995) and, in the American coot (Fulica americana), increased androgen levels are likely to be important in simultaneous vocal transitions and changes in bill-shield coloration (Cosens, 1981). In woodhoopoes, juvenile males begin to lose their distinctive brown throat patch around the same time that their voice breaks (pers. obs.). The loss of this throat patch is likely to be controlled hormonally, and voice breaking may also be a consequence of changes in male hormonal levels at this stage in development.

Some studies investigating the ontogeny of bird song have revealed that vocalisations often become more stereotyped with age (Marler \& Peters, 1982, but see Schleidt \& Shalter, 1973; Elowson et al., 1992). In the green woodhoopoe, there was a suggestion of increasing stereotypy with age in some vocal parameters of the kek call, but the results were not significant after Bonferroni correction. Sex differences in the length of call elements have 
also been reported in a number of species (e.g. Bretagnolle, 1989; Rosenfield \& Bielefeldt, 1991; Baptista et al., 1994). However, the duration of kek-call elements did not differ between the sexes in the green woodhoopoe, as was also found to be the case in Bulwer's petrel (Bulweria bulwerii; James \& Robertson, 1985) and Cory's shearwater (Calonectris diomedea; Bretagnolle \& Lequette, 1990). Thus, the only significant age-related change in woodhoopoe kek-call acoustic structure is the sudden decrease in male fundamental frequency.

\section{References}

Abs, M. (1980). Zur Bioakustik des Stimmbruchs bei Vögeln. —Zool. J. Physiol. 84, p. 289382.

Ballintijn, M.R. \& ten Cate, C. (1997a). Sex differences in the vocalisations and syrinx of the collared dove (Streptopelia decaocto). - Auk 114, p. 22-39.

- — \& - - (1997b). Vocal development and its differentiation in a non-songbird: the collared dove (Streptopelia decaocto). - Behaviour 134, p. 595-621.

Baptista, L.F., Trail, P.W., Dewolfe, B.B. \& Morton, M.L. (1994). Singing and its functions in female white-crowned sparrows. - Anim. Behav. 26, p. 511-524.

Beckers, G.J.L., Suthers, R.A. \& ten Cate, C. (2003a). Pure-tone birdsong by resonance filtering of harmonic overtones. - Proc. Natl. Acad. Sci. USA 100, p. 7372-7376.

- - , - — \& - (2003b). Mechanisms of frequency and amplitude modulation in ring dove song. - J. Exp. Biol. 206, p. 1833-1843.

Bretagnolle, V. (1989). Calls of Wilson's storm petrel: functions, individual and sexual recognition, and geographic variation. - Behaviour 111, p. 98-112.

— — \& Lequette, B. (1990). Structural variation in the call of Cory's shearwater (Calonectris diomedea, Aves, Procellariidae). - Ethology 85, p. 313-323.

Catchpole, C.K. (1982). The evolution of bird sounds in relation to mating and spacing behaviour. - In: Acoustic communication in birds, vol. 1 (D.E. Kroodsma \& E.H. Miller, eds). Academic Press, New York, p. 297-319.

— — \& Slater, P.J.B. (1995). Bird song: biological themes and variations. — Cambridge University Press, Cambridge.

Cornell Laboratory of Ornithology (1993). CANARY 1.2. - Bioacoustics Research Program, New York.

Cosens, S.E. (1981). Development of vocalisations in the American coot. — Can. J. Zool. 59, p. 1921-1928.

Dooling, R.J. (1982). Auditory perception in birds. — In: Acoustic communication in birds, vol. 1 (D.E. Kroodsma \& E.H. Miller, eds). Academic Press, New York, p. 95-130.

Du Plessis, M.A. (1989). The influence of roost-cavity availability on flock size in redbilled woodhoopoes. - Ostrich Suppl. 14, p. 97-104.

- — (1991). The role of helpers in feeding chicks in cooperatively breeding green (redbilled) woodhoopoes. - Behav. Ecol. Sociobiol. 28, p. 291-295.

Elowson, A.M., Snowdon, C.T. \& Sweet, C.J. (1992). Ontogeny of trill and J-call vocalisations in the pygmy marmoset, Cebuella pygmaea. - Anim. Behav. 43, p. 703-715. 
Farquhar, C.C. (1993). Individual and intersexual variation in the alarm calls of the whitetailed hawk. - Condor 95, p. 234-239.

Fee, M.S., Shraiman, B., Pesoran, B. \& Mitra, P.P. (1998). The role of nonlinear dynamics of the syrinx in the vocalisations of a songbird. - Nature 395, p. 67-71.

Fletcher, N.H. \& Tarnopolsky, A. (1999). Acoustics of the avian vocal tract. - $\underline{\text { J. Acoust. }}$ Soc. Am. 105, p. 35-49.

Fry, C.H., Keith, S. \& Urban, E.K. (1988). The birds of Africa, vol. 3. - Academic Press, London.

Fusani, L., Beani, L. \& Dessi Fulghieri, F. (1994). Testosterone affects the acoustic structure of the male call in the grey partridge (Perdix perdix). - Behaviour 128, p. 301-310.

Gosler, A.G., Greenwood, J.J.D., Baker, J.K. \& Davidson, N.C. (1998). The field determination of body size and condition in passerines: a report to the British Ringing Committee. - Bird Study 45, p. 92-103.

Groothuis, T. (1989). On the ontogeny of display behaviour in the black-headed gull: I. The gradual emergence of the adult forms. - Behaviour 109, p. 76-124.

- — \& Meeuwissen, G. (1992). The influence of testosterone on the development and fixation of the form of displays in two age classes of young black-headed gulls. Anim. Behav. 43, p. 189-208.

— - Morimando, F. \& Hutchison, R.E. (1993). Testosterone and the development of postural and vocal displays in the barbary dove. - In: Proceedings of the international conference on hormones, brain and behaviour (J. Signoret, F. Fabre \& J. Balthazart, eds). Instaprint SA, Tours, p. 81-82.

Harries, M., Hawkins, S., Hacking, J. \& Hughes, I. (1998). Changes in male voice at puberty: vocal fold length and its relationship to the fundamental frequency of the voice. - $\underline{\mathrm{J}}$. Laryngol. Otol. 112, p. 451-454.

James, P.C. \& Robertson, H.A. (1985). The call of Bulwer's petrel (Bulweria bulwerii), and the relationship between intersexual call divergence and aerial calling in nocturnal Procellariiformes. - Auk 102, p. 878-882.

Kroodsma, D.E. (1982). Learning and the ontogeny of sound signals in birds. - In: Acoustic communication in birds, vol. 2 (D.E. Kroodsma \& E.H. Miller, eds). Academic Press, New York, p. 1-23.

— — \& Miller, E.H. (1996). Ecology and evolution of acoustic communication in birds. Cornell University Press, Ithaca.

Lade, B.I. \& Thorpe, W.H. (1964). Dove songs as innately coded patterns of specific behaviour. - Nature 202, p. 366-368.

Ligon, J.D. \& Ligon, S.H. (1978). The communal social system of the green woodhoopoe in Kenya. — Living Bird 17, p. 159-197.

— — \& — — (1990). Green woodhoopoes: life history traits and sociality. — In: Cooperative breeding in birds (P.B. Stacey \& W.D. Koenig, eds). Cambridge University Press, Cambridge, p. 31-66.

Marler, P., Kreith, M. \& Willis, E. (1961). An analysis of testosterone-induced crowing in young domestic cockerels. - Anim. Behav. 10, p. 48-54.

— — \& Peters, S. (1982). Subsong and plastic song: their role in the vocal learning process. - In: Acoustic communication in birds, vol. 2 (D.E. Kroodsma \& E.H. Miller, eds). Academic Press, New York, p. 25-50.

Myers, J.A. (1917). Studies on the syrinx of Gallus domesticus. - J. Morphol. 29, p. 165214. 
Nottebohm, F. \& Nottebohm, M.E. (1971). Vocalisations and breeding behaviour of surgically deafened ring doves (Streptopelia risoria). — Anim. Behav. 19, p. 313-327.

Nowicki, S. (1987). Vocal tract resonances in oscine bird sound production: evidence from birdsong in a helium atmosphere. - Nature 325, p. 53-55.

Owens, I.P.F. \& Short, R.V. (1995). Hormonal basis of sexual selection in birds: implications for new theories of sexual selection. - Trends Ecol. Evol. 10, p. 44-47.

Platz, F. (1974). Untersuchungen über die Ontogenie von Ausdruckbewegungen und Lautäußerungen bei der Kolbenente (Netta rufina Pallas) mit einem Beitrag zur Anatomie des Stimmapparates. - Z. Tierpsychol. 36, p. 293-428.

Podos, J. (1997). A performance constraint on the evolution of trilled vocalisations in a songbird family (Passeriformes: Emberizidae). — Evolution 51, p. 537-551.

Radford, A.N. (2003). Territorial vocal rallying in the green woodhoopoe: influence of rival group size and composition. - Anim. Behav. 66, p. 1035-1044.

- - (2004). Vocal co-ordination of group movement by green woodhoopoes (Phoeniculus purpureus). - Ethology 110, p. 11-20.

- _ (in press). Vocal mediation of foraging competition in the cooperatively breeding green woodhoopoe (Phoeniculus purpureus). — Behav. Ecol. Sociobiol.

— — \& du Plessis, M.A. (2003). Bill dimorphism and foraging niche partitioning in the green woodhoopoe. - J. Anim. Ecol. 72, p. 258-269.

Rice, W.R. (1989). Analysing tables of statistical tests. — Evolution 43, p. 223-225.

Robisson, P. (1992). Vocalisations in Aptenodytes penguins: application of the two-voice theory. - Auk 109, p. 654-658.

Rosenfield, R.N. \& Bielefeldt, J. (1991). Vocalisations of Cooper's hawk during the preincubation stage. - Condor 93, p. 659-665.

Ryan, M.J. \& Brenowitz, E.A. (1985). The role of body size, phylogeny, and ambient noise in the evolution of bird song. - Am. Nat. 126, p. 87-99.

Schleidt, W.M. \& Shalter, M.D. (1973). Stereotypy of a fixed action pattern during ontogeny in Coturnix coturnix coturnix. - Z. Tierpsychol. 33, p. 35-37.

Ten Thoren, B. \& Bergmann, H. (1987). Veränderung und Konstanz von Merkmalen in der jugendlichen Stimmentwicklung der Nonnengans (Branta leucopsis). — Behaviour 100 , p. 61-91.

Würdinger, I. (1970). Erzeugung, Ontogenie und Funktion der Lautäußerungen bei vier Gänsearten (Anser indicus, A. caerulescens, A. albifrons und Branta canadensis). Z. Tierpsychol. 27, p. 257-302. 